\title{
AiMT
}

Advances in Military Technology

Vol. 11, No. 2 (2016), pp. 261-263

ISSN 1802-2308, eISSN 2533-4123

DOI 10.3849/aimt.01148

Book Review

\section{Air and Missile Defense Systems Engineering}

\author{
Warren J. Boord and John B. Hoffman
}

The humankind has been trying to find a way how to overpower its rivals from time out of mind. More and more sophisticated weapons have been appearing during the $20^{\text {th }}$ century and this effort had come almost to perfection: humankind is now able to destroy itself completely. The instruments for it are weapons of mass destruction (WMD), and the devices which deliver them to the "right place" are airplanes and ballistic missiles (BM) in particular. This "self-destroying" epoch started fully during the World War Two (WW2) and our World has been on the verge of nuclear war several times since then. Therefore, as long as the WMD and their transportation equipment - BM exist, the appropriate defence will be necessary. A possible approach to deal with this very complex problem is discussed here - namely from the management and technical point of view - by authors W.J. Boord and J.B. Hoffmann.

Boord, as a former U.S. Air Force officer and later an experienced technician in the field of weapon systems, has utilized his know-how many times. He has been focusing particularly on threat analysis, air-threat engagement and guidance law design.

Hoffman has had more than 30 years of engineering experience in the field of radar systems, especially the air and missile defence ones. He has been specializing in ship-boarded defence systems, their combat performance, modelling and simulation.

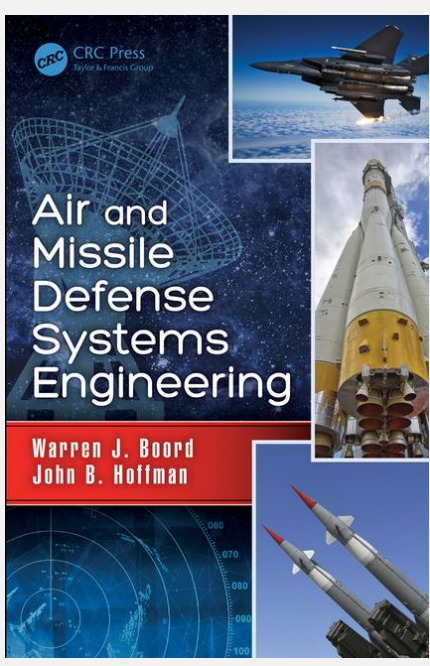

\section{CRC Press}

251 pages

\section{Hardback:}

ISBN 978-1-4398-0670-8

\section{eBook:}

ISBN 978-1-4398-0671-5

DOI 10.1201/b19671-1

\section{Language of Publication:}

English

\section{Subject:}

Air Defence

Missiles 


\section{General outlook}

Book Air and Missile Defense Systems Engineering has an ambition to address the needs of military people, managers and producers, particularly when they start a new defence project, or a modernisation is planned. From analyses of the managers' approach at the beginning, it continues via the concept of operation (CONOPS) view; further on, it leads the readers through system performance requirements and it ends up by an analysis of both physical and mathematical principles.

In comparison to other writings, the perspective of this one is more complex - thanks to the pre-acquisition and management problem solving. On the other hand, the whole book shows authors' respectable backgrounds in the ballistic missile defence. For example in [1] the problems of kinematics and time-space windows are solved deeply, without considering other aspects. A different perspective can be found e.g. in [2], where the operational view and battle effectiveness are explained, including corresponding mathematical apparatuses.

Other outputs produced by NATO, or U.S. Ballistic Missile Defence Organizations (namely in their unclassified versions) address either a narrow spectrum of political / military specialists or lay public. Usually there are neither mathematical-physical principles, nor exact calculation with relevant results. The concrete numbers concerning e.g. radar crosssection, energy required for aircraft / missile body penetration etc. is hardly to find at all.

Authors proceed to solve air and ballistic missile (ABM) defense system issue by phasing it according to its life cycle. ABM system engineering planning is segmented into seven phases:
A. Pre-phase: Project Definition;
B. Systems Requirements;
C. Preliminary Design;
D. Detailed Design;
E. Engineering, Manufacturing, Development, Integration, Testing;
F. Operations \& Sustainment;
G. Retirement \& Disposal.

Authors have focused on the phases "A" and "B", whilst the rest is left for next elaboration. Thus, the main emphasis is especially put on systems requirements, including deep theoretical and mathematical reasoning and validation.

\section{Constructive Criticism}

In this book we can find and understand deep knowledge and experience from ballistic missile defence systems engineering. Nevertheless, from my point of view the title "Air and Missile Defense..." could be reduced to "Missile Defense..." only. The Air defence (AD) generally covers problems concerning aeroplanes, helicopters, cruise missiles, UAVs, today "non-standard" threats like rocket-artillery and mortar ammunition (RAM) etc. It means that a broader spectrum of surveillance means, tracking radars and effectors have to be deployed to counter them. Thus, especially thanks to ship-boarded missile defence applications mentioned here, AD problems are assessed more or less one-sidedly. Nevertheless, the indisputable fact is that the mathematical apparatus and physical principles are generally applicable and valid.

From my point of view, this book has been created by synergy of the whole range of works, experiment results, modelling etc. Obviously, the graphic outputs were produced in 
colour in the original version. However, this book is printed black \& white, whereas textual interpretation refers to colour lines, areas ... Similarly, some figures and block-diagrams, especially those made in inverse form (white on black) are hindering fluent reading and understanding.

\section{Conclusion}

The overall general impression from the book is that this is the right book for BMD specialists that want to understand the planning process and technical background. However, if the readers needed to plunge into it, they would have to have solid knowledge of electric, radar and air defence generally.

From the pedagogical point of view, this book can be used successfully as a reference material for Master's or PhD students to widen their mastery in the anti-ballistic missile field.

To sum up, it is worthy to have this material in all scientific, technical or special libraries where the problems of ballistic missile defence are solved.

\section{References}

[1] Sequard-Base, P. Raketenabwehr-Bedrohung-Verteidigung Eine physikalisch-technische Annäherung (in German). Wien: Landesverteidigungsakademie Wien, Büro für Sicherheitspolitik, 2003, ISBN 3-902275-06-5, 246 p.

[2] Urbánek, K. Missile Defence (in Czech) [Habilitation Thesis]. Brno: Military Academy in Brno, 2001.

[3] Macfadzean, R.H.M. Surface-Based Air Defense System Analysis. Norwood: Artech House, 1992, ISBN 0-89006-451-2, 404 p.

COL (ret.) Miroslav Krátký University of Defence Czech Republic 